\title{
Morphodynamic Modelling of a Shoreface Nourishment at Egmond-aan-Zee, The Netherlands
}

\author{
Christophe BRIERE ${ }^{1}$, Maarten van ORMONDT ${ }^{1}$, Dirk-Jan WALSTRA ${ }^{1,2}$ \\ ${ }^{1}$ Deltares - WL | Delft Hydraulics, PO Box 177, 2600 MH Delft, The Netherlands. \\ christophe.briere@deltares.nl. \\ ${ }^{2}$ Technical University of Delft, Civil Engineering, Stevinweg 1, $2628 \mathrm{CN}$ Delft, The \\ Netherlands.
}

\begin{abstract}
:
This study aims at investigating the morphodynamic effect of the shoreface nourishment using profile (2DV) and area (3D) DELFT3D - MOR modelling approaches. The research model is based on the engineering sand transport formulations of TRANSPOR2004 model, which include both wave-related and current-related components, with a numerical intra-wave approach.

Tide and wave schematizations are defined to minimize the computation time of the simulation, and to enable the use of a morphological factor, which assists in dealing with the difference in time-scales between hydrodynamic and morphological developments. Calibrated models are applied to support the design of future shoreface nourishments. The efficiency of three different nourishment designs is evaluated. The application suggests that the more appropriate design consists of nourishing the seaward slope of the outer bar with a height of $-5 \mathrm{~m}$.
\end{abstract}

\section{Keywords:}

Shoreface nourishment - Morphodynamic modelling - DELFT3D numerical model - TRANSPOR2004 sediment transport formulations

\section{Introduction}

Although beach nourishment policy in the Netherlands has been generally successful in maintaining the 1990 shoreline, nourishments at several locations along the North Sea coast have disappeared after 2 years, whereas they were expected to remain during at least 5 years. To support management on these coastal stretches, it is imperative to increase the knowledge on the effects that shoreface nourishments have on the coast on time scales of weeks (storms) to years (cyclic bar behaviour). To achieve this goal, a numerical study can be setup, which captures small-scale processes forced by waves and currents thought to be relevant for cross-shore and alongshore sandbar behaviour. Furthermore, 
calibrated/validated models can be used to evaluate the efficiency of alternative designs, giving insights on the most suitable implementation of sand nourishments in the coastal zone.

In this study, the Egmond region (The Netherlands), presented in section 2, has been selected because this area has been the focus of many field experiments (COAST 3D project, Soulsby, 2001) and model validation studies in recent years (see e.g. Van Duin et al., 2004). Moreover, a shoreface nourishment at the outer bar (- $5 \mathrm{~m}$ depth) was implemented in 2004. Profile (2DV) and area (3D) approaches have been set-up using the DELFT3D - MOR model (presented in section 3). The profile model has been calibrated through a sensitivity analysis of the main settings and of different representations of waves and tides (sections 5). Results have been systematically compared to observed bathymetric data. The area model has been used to validate the choice of the parameter settings. The models have been applied to support design of future shoreface nourishments (section 6). The conclusions are addressed in section 7.

\section{Site description}

At the end of the nineties, Egmond-aan-Zee (Figure 1) was identified as one of the main erosional hotspots of the Holland coast. As a result, shore- and beach nourishments were designed to improve the coastline stability. The two most recent nourishments were applied in 1999 and 2004, and placed under water as shoreface nourishment. The applied volumes were respectively $1.4 \mathrm{Mm}^{3}$ and 1.8 $\mathrm{Mm}^{3}$. In 2005, an additional beach nourishment of $0.5 \mathrm{Mm}^{3}$ was applied. The Figure 1 gives an overview of the location of the shoreface nourishments, respective to the alongshore beach poles (JARKUS transects).
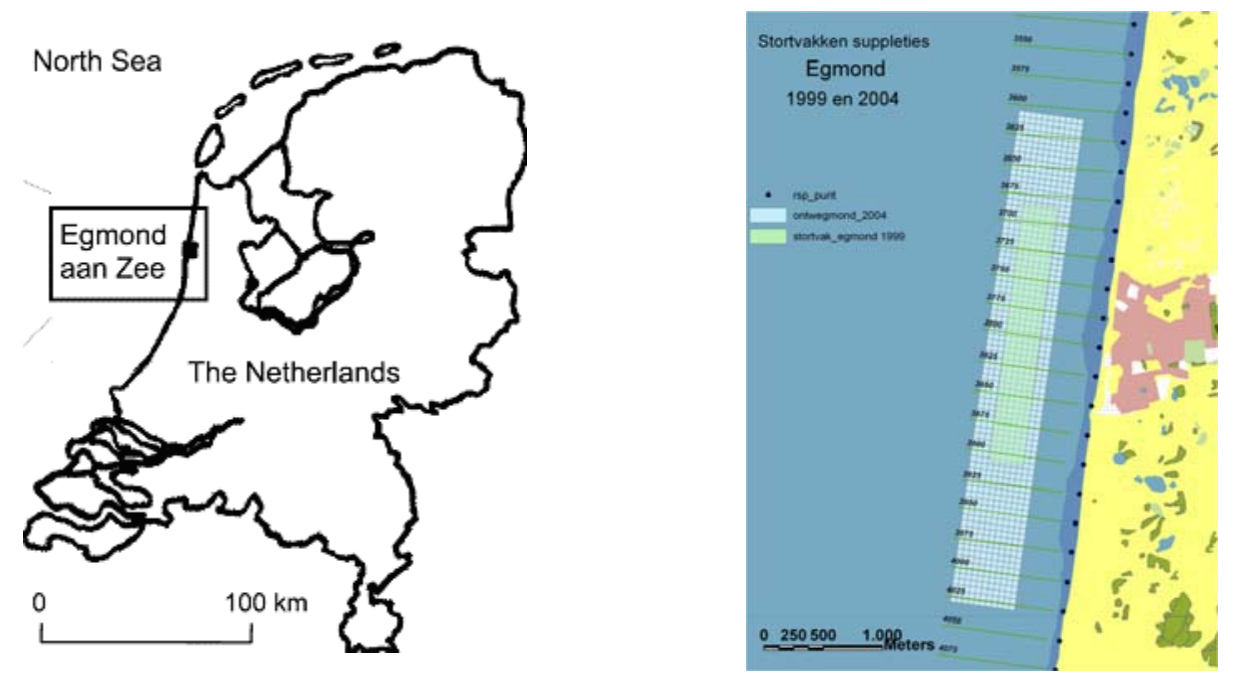

Figure 1. Location of nourishments at Egmond-aan-Zee 
Egmond-aan-Zee is located between beach poles 37.25 and 38.50. At Egmondaan-Zee, the mean tidal range varies between $1.2 \mathrm{~m}$ in the neap cycle to 2.1 in the spring cycle. The tidal peak current is about $0.5 \mathrm{~m} / \mathrm{s}$ in the offshore zone, with the flood current to the North slightly larger than the ebb current directed to the South. The mean monthly offshore wave height has a seasonal character, and varies from about $1 \mathrm{~m}$ in the summer months (May to August) to about 1.5 to 1.7 $\mathrm{m}$ in the autumn and winter (October to January). The mean wave height can reach $5 \mathrm{~m}$ at $15 \mathrm{~m}$ depth, during major storms. The beach width is about $100 \mathrm{~m}$ to $125 \mathrm{~m}$ with a slope between 1:30 and 1:50. Two main longshore breaker bars run parallel to the shoreline most of the time. The inner bar is located $200 \mathrm{~m}$ from the shoreline at $2 \mathrm{~m}$ below the mean sea water level (MSWL), whilst the crest of the outer bar is located at about $500 \mathrm{~m}$ from the shore at $4 \mathrm{~m}$ below the MSWL. The inner bar is separated from the outer one by a wide trough. The area is characterised by medium well-sorted sands, although in the trough between the inner and outer bars, the sand is coarser (of about $0.5 \mathrm{~mm}$ ) and has a moderate sorting. The cross-shore slope amounts to $1: 100$, and the median grain size is about $0.2 \mathrm{~mm}$. Figure 3 displays the bathymetry as it was monitored in November 2004.

\section{Delft3D model}

For this study, profile (2DV) and area (3D) modelling approaches are considered using the DELFT3D - MOR numerical model (Lesser et al., 2004; Van Rijn et al., 2007). The model is based on the engineering sand transport formulations of TRANSPOR2004 model (Van Rijn, 2007a, b), which include both wave-related and current-related components, with a numerical intra-wave approach.

The hydrodynamic module DELFT3D-FLOW is a widely used free surface model that solves the SWE in the primitive variables velocity and water level, both in two and three dimensions on a staggered finite difference grid with a terrainfollowing $\sigma$-coordinate system in the vertical (in a $3 \mathrm{D}$ application) as well as a fixed vertical coordinate. DELFT3D-FLOW SWE solver is based on an Alternating Direction Implicit method (Stelling and Leendertse, 1991). In the generalized version of the system, it poses no integration time step constraints with regard to the stability of the numerical computation allowing for a larger integration time step and thereby reducing the computation time required. Recent years, much effort has been dedicated to the improvement of the morphodynamic module DELFT3D - MOR, based on the engineering sand transport formulations of TRANSPOR2004 model (Van Rijn, 2007a, b). A general bed load transport equation includes now both wave-related and current-related components, with a numerical intra-wave approach (based on Isobe and Horikawa, 1982). Besides, the 
suspended transport is computed as the sum of the current-related transport of sediment by the mean current, including the effect of wave stirring on the sediment load, and of the wave-related transport, resulting from the asymmetric oscillatory wave motion near the bed in shoaling waves. Moreover, research efforts in 2DV profile modelling (Roelvink et al., 1995) suggest promising ways of improving the predictive capability of process-based models, using wave energy decay concepts. The DELFT3D - MOR model has been updated so that it now includes a surface roller model (Reniers et al., 2004) and two breaker delay concepts (Roelvink et al., 1995; Reniers et al., 2004).

\section{Model set-up}

\subsection{Grid schematisations}

Profile and area grids have been set-up based on the bathymetry surveys carried out at Egmond-aan-Zee. The profile grid was constructed to cover the active zone in the cross-shore direction and has its seaward boundary at the $12 \mathrm{~m}$ depth contour. The grid spacing decreases from $60 \mathrm{~m}$ at the seaward boundary to $20 \mathrm{~m}$ in the surf zone. The landward boundary includes the beach dune at a height of about $3.5 \mathrm{~m}$. A $12 \sigma$-layers distribution has been defined in the vertical direction with highest resolutions at the bed and near the water surface, decreasing towards the middle of the water column. The area grid extension is of $6500 \mathrm{~m}$ by $1300 \mathrm{~m}$, with a constant horizontal grid spacing of $40 \mathrm{~m}$ and $20 \mathrm{~m}$ in the longshore and cross-shore directions, respectively. The vertical $\sigma$-layers distribution is taken identical to that of the profile model.

\section{$\underline{4.2}$ Tide and wave schematisations}

The tidal information consists on either (i) a real-time serie of water levels (including surges), (ii) an astronomic tide, or (ii) a harmonic tide. When adopting a harmonic representation, a complete tidal cycle (e.g. neap-spring tide) should be ideally simulated. This leads however to an unacceptable high computational effort. Then, an alternative tide, so-called morphological tide, resulting in a reliable description of the net sediment transports, has been defined. At the northern and southern boundaries, Neumann conditions have been imposed, which consist of longshore water level gradients.

The wave climate consists of a selection of wave conditions in order to limit the computational effort. A sensitivity analysis has been performed to define the optimal number of wave conditions and the way the selection should be obtained : the reduction was achieved by either (i) ensuring identical gross northward and 
southward transports, or (ii) ensuring identical offshore and onshore transports, by means of scaling the selected wave conditions. Tests have been performed considering either 5 or 10 schematised wave climates.

\subsection{Morphological set-up}

The schematized wave climate is referred to as a morphological wave climate and is applied with tidal boundary conditions prescribed as a morphological tide, based on harmonic components. This representation of wave and tide enables the use of a morphological factor, MorFac, which is a device used to assist in dealing with the difference in time-scales between hydrodynamic and morphological developments. It works very simply by multiplying the changes in bed sediments by a constant factor, thereby effectively extending the morphological time step. This technique is very similar to the "elongated tide" technique proposed by Latteux (1995) and implies that long morphological simulations can be achieved using hydrodynamic simulations of only a fraction of the required duration.

\section{Calibration}

The present study is based on a combination of profile and area modelling approaches. Modelling efforts have been limited to the period of 04/11/04 to $30 / 11 / 04$. Results have been systematically compared to observed bathymetric data. The profile model has been calibrated, based on a sensitivity analysis of the main settings and of different representations of waves and tides. The area model has been used for validation purpose, before its application to support design of future shoreface nourishment.

\subsection{Profile modelling}

The morphological developments obtained using different representations of tides are plotted in Figure 2. Although the figure displays unrealistic behaviours of the new outer bar, with an significant off-shore movement and a large increase of the height, the offshore migration and flattening of the former outer bar is well reproduced by the model. The influence of the tidal schematisation is limited. It is especially promising to see that the harmonic tide (essentially one representative tidal cycle referred to as the morphological tide) shows a large consistency with the astronomic tide (tidal hindcast using astronomical components). When considering different wave schematisations (see paragraph 4.2), the overall behaviour is very similar. This is a promising finding because the inclusion of each additional wave condition leads to a proportional increase in morphological simulation time. 


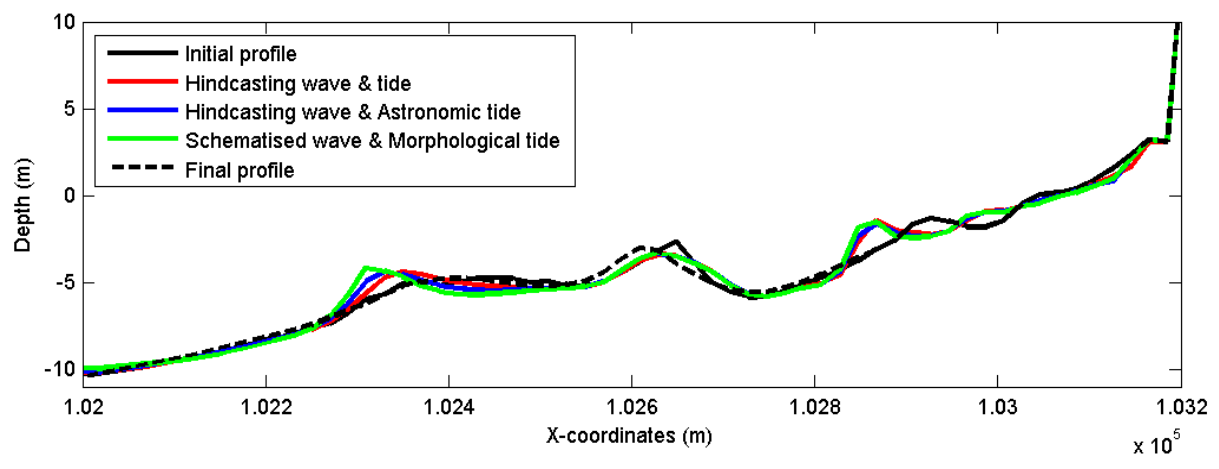

Figure 2. Profile development 04/11/04 to 30/11/04

\subsection{Area modelling}

Tidal boundary conditions and wave conditions are taken identical to those of the profile model. Other input parameters are also derived from the optimum settings of the calibrated profile model. The bathymetric evolution of November 2004 at Egmond-aan-Zee was dominated by longshore transport processes. Two northwesterly storms induced a southward migration of the entire complex of bars and troughs of approximately 500 meters. Furthermore, both the inner and former outer bar have migrated seaward. Figure 3 displays the computed bathymetric evolution considering only one storm condition, avoiding instabilities which develop during the calmer wave conditions.

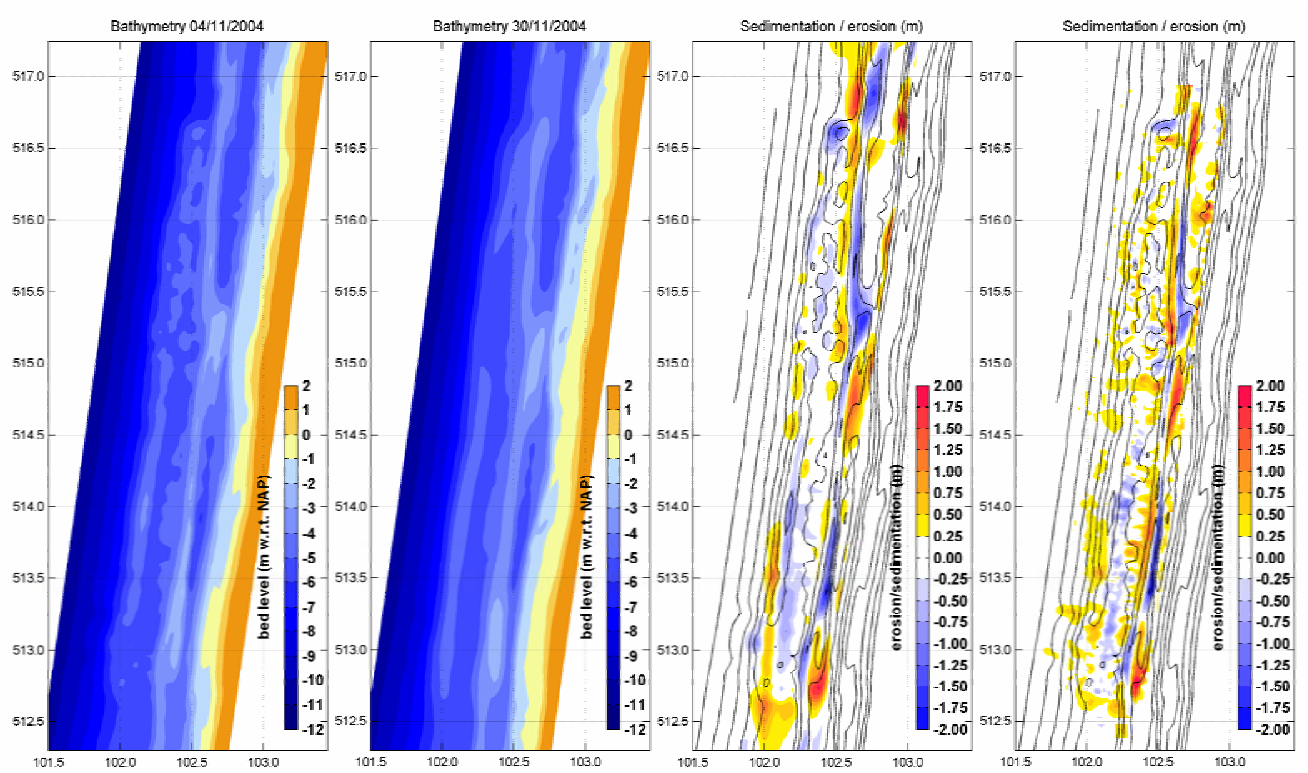

Figure 3. Initial bathymetry of 4 November 2004 (left panel), simulated final bathymetry using the storm wave condition only (middle left panel), computed erosion/sedimentation (middle right panel) and observed one (right panel). 
These results show a promising resemblance with the observed bathymetric changes. The behaviour of the former outer bar appears to be well predicted with a correct onshore and offshore migration of the bar at the right locations.

\section{Application}

The calibrated models have been applied to support the design of future shoreface nourishments. Three alternative nourishment designs, based on a volume of 400 $\mathrm{m}^{3}$ per meter, are considered: (i) a nourishment against the seaward slope of the outer bar with same height (- $2.7 \mathrm{~m}$ depth) as the outer bar - Alternative case 1 -, (ii) a nourishment against the seaward slope of the outer bar, constructed by assuming a height of $-5 \mathrm{~m}$ - Alternative case 2 -, and (iii) a nourishment in which the trough between the outer and inner bars is filled up - Alternative case $3-$. The applied annual wave climate (Walstra et al., 2004) consists of two storm and two moderate wave conditions from a southwesterly $\left(224^{\circ} \mathrm{N}\right)$ and a northwesterly direction $\left(334^{\circ} \mathrm{N}\right)$. All model settings are identical to those applied previously to ensure a consistent application of the model with insights given by the analysis (comparison area/profile models).

\section{$\underline{6.1}$ Profile modelling}

The profile developments after one year are displayed in Figure 4. The bathymetric evolution for the reference case (Alternative case 0) displays a flattening of the profile without significant outer bar migration, either in offshore or onshore direction. Such flattening is observed in all alternative cases which have been considered. In general, the profile development exhibits an onshore migration of the outer bar. Evolution in shallow waters (between 0 and $300 \mathrm{~m}$ from the origin of the profile) remains unrealistic. The main volume changes occur in shallow waters in section $0-400 \mathrm{~m}$ for all cases. The only case displaying a volume increase in both sub-sections $200-400 \mathrm{~m}$ and $400-600 \mathrm{~m}$ is the design with a nourishment against the seaward slope of the outer bar, constructed by assuming a height of $-5 \mathrm{~m}$ (alternative case 2). Moreover, cumulative volume change, in sub-sections $200-400 \mathrm{~m}$ and $400-600 \mathrm{~m}$, is maximum when adopting this design (alternative case 2). Such increase is compensated by a volume loss in sub-section 600-800 m. In deeper waters, the profile developments display similar behaviour for all cases.

\subsection{Area modelling}

The initial and final bathymetries for the Alternative case 2 are displayed in Figure 5. After one year, the nourishment has diffused considerably and the effect on the outer bar is very limited. However, shoreward of the outer bar, the 
nourished alongshore section has experienced considerable sedimentation. After one year, the alongshore position of the nourishment has not changed significantly. Although there is a northward residual transport, the nourishment is mainly diffused. The cross-shore profile along the central cross-section (middle of the nourished area) exhibits the development of two bars: one at the seaward extent of the nourishment, and one at the position of the former outer bar. This behaviour is in qualitative agreement with the observed development of the shoreface nourishment at Egmond (Van Duin et al., 2004).

\section{$\underline{6.3 \text { Discussion }}$}

Alternative case 2 suggests an on-going development as follows: the nourished sub-section between 600 and $800 \mathrm{~m}$ from the origin of the profile seems to split in two parts, developing the outer bar at approximately $700 \mathrm{~m}$ from the origin of the profile, and feeding the inner bar, which might shift seawards as well, at 300-400 $\mathrm{m}$ from the origin of the profile. Such development is characteristic of a shoreface nourishment, protecting the coast by increasing volumes in the upper part of the beach.
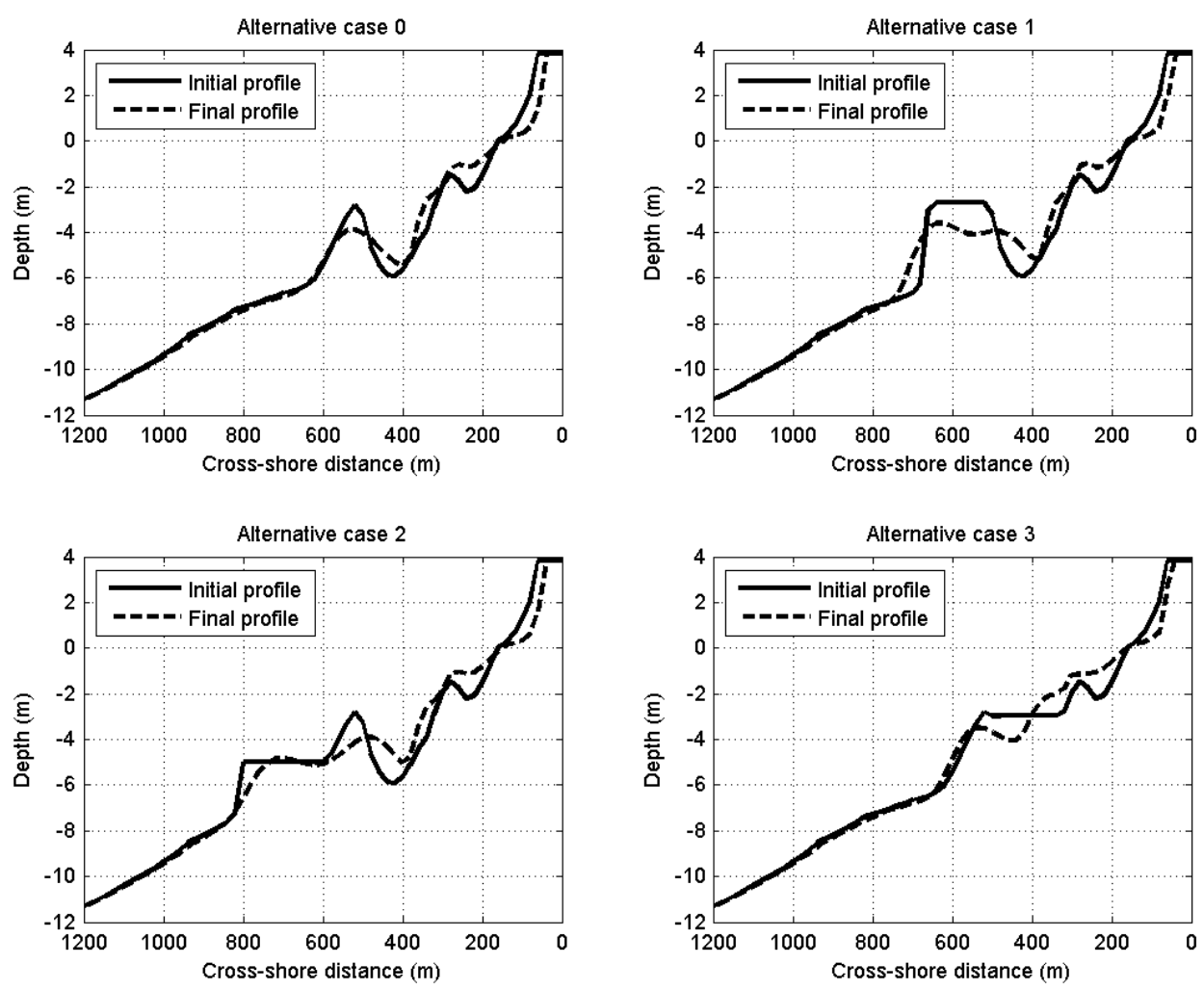

Figure 4. Profile developments after 1 year for different nourishment design. 

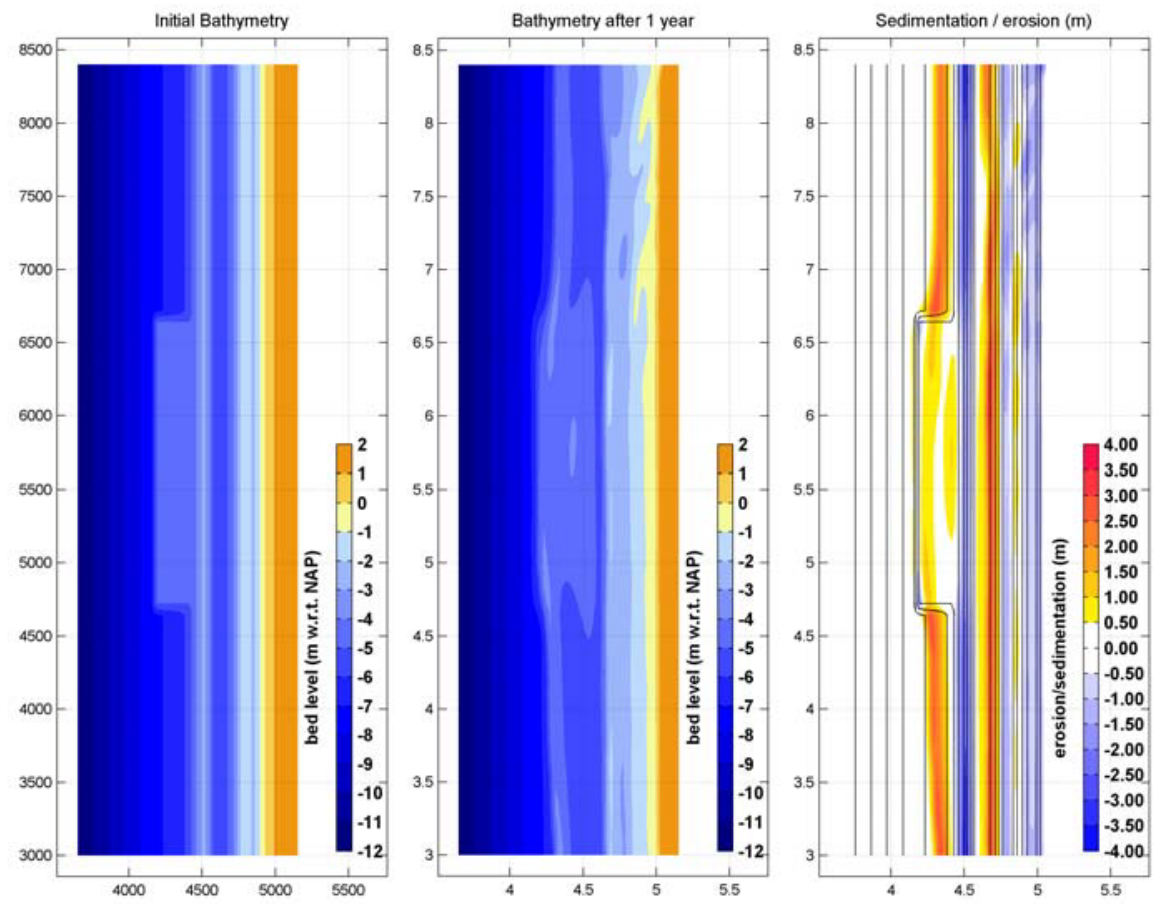

Figure 5. Initial bathymetry (left panel), computed final bathymetry (middle panel) and computed erosion/sedimentation (right panel).

\section{Conclusion}

The modelling of the Egmond nourishment has been performed by first applying a profile model to investigate the sensitivity to various boundary schematisations (tide and waves). Subsequently, this model has been used to test various model parameters. The final model settings have been used to set-up an area model. Although the offshore migration and generation of a pronounced nourished bar are overestimated by the profile model, the offshore movement of the (former) outer bar and its reduced crest height are correctly predicted. The influence of the tide and wave schematisations are limited. It is especially promising to see that the harmonic tide (essentially one representative tidal cycle) shows a large consistency with the astronomic tide (tidal hindcast using astronomical components). Regarding the wave schematisation, it is also a promising finding because the inclusion of a wave condition leads to a proportional increase in morphological simulation time. Using the area model, the predicted sedimentation-erosion patterns are very similar to the observations. The absolute sedimentation and erosion values are however over-estimated in the bar region. The application of models suggests that the most appropriate nourishment design would be by nourishing the seaward slope of the outer bar with a height of $-5 \mathrm{~m}$ (alternative case 2). 


\section{References}

ISOBE M., HORIKAWA K. (1982). Study on water particle velocities of shoaling and breaking waves, Coastal Engineering in Japan, Vol. 25, p. 109-123. LATTEUX B. (1995). Techniques for long-term morphological simulation under tidal action. Marine Geology 126, 129- 141.

LESSER G.R., ROELVINK J.A., Van KESTEREN J.A.T.M., STELLING G.S. (2004). Development and validation of a three-dimensional morphological model. Coastal Engineering, vol. 51, p. 883-915.

RENIERS A.J.H.M., ROELVINK J.A., THORNTON E.B. (2004). Morphodynamic modeling of an embayed beach under wave group forcing. J. Geophys. Res. 109 (C01030).

ROELVINK J.A., MEIJER T.J.G.P., HOUWMAN K., BAKKER R., SPANHOFF R. (1995). Field validation and application of a coastal profile model. In: Dally, W.R., Zeidler, R.B. (Eds.), Proc. 2nd Int. Conf. on Coastal Dynamics '95. ASCE, New York, pp. 818-828.

SOULSBY R. (2001). Sediment Transport and Morphodynamics on Complex Coastlines-The Coast3D Project. Int. Coastal Dynamics Conference. ASCE. Lund. Sweden.

STELLING G.S., LEENDERTSE J.J. (1991). Approximation of Convective Processes by Cyclic AOI methods, Proceeding 2nd ASCE Conference on Estuarine and Coastal Modelling, Tampa.

VAN DUIN M.J.P., WIERSMA N.R., WALSTRA D.J.R., VAN RIJN L.C., STIVE M.J.F. (2004). Nourishing the shoreface: observations and hindcasting of the Egmond case, The Netherlands. Journal of Coastal Engineering, Vol 51, pp 813-837.

VAN RIJN L.C. (2007a). A unified view of sediment transport by current and waves, Part I: Initiation of motion, bed roughness and bed load transport. Journal of Hydraulic Engineering, ASCE, vol. 133, n6, p. 649-667.

VAN RIJN L.C. (2007b). A unified view of sediment transport by current and waves, Part II: Suspended transport. Journal of Hydraulic Engineering, ASCE, vol. 133, nº, p. 668-689.

VAN RIJN L.C., WALSTRA D.J., VAN ORMONDT M. (2007). A unified view of sediment transport by current and waves, Part IV: Application of a morphodynamic model. Journal of Hydraulic Engineering, ASCE, vol. 133, n ${ }^{\circ} 7, \mathrm{p}$. 776-793.

WALSTRA D.J, VAN ORMONDT M., ROELVINK J.A. (2004). Shoreface Nourishment Scenarios, WL | Delft Hydraulics report Z3748.21. 